\title{
Cultura afetiva: a construção do ser brincante no contexto urbano externo 1
}

\section{Cultura afectiva: la construcción del ser bromeante en el contexto urbano externo}

\section{Affective culture: the construction of being playful in the external urban context}

\author{
Nadja Maria Mourão ${ }^{2}$ \\ Ana Célia Carneiro Oliveira ${ }^{3}$
}

\begin{abstract}
Resumo
A transformação dos espaços em lugares de afeto é uma possibilidade que advêm das relações em divertimento e brincadeiras. Essa relação pode proporcionar uma reflexão sobre o comportamento humano e gerar novos caminhos para a participação social. São utilizados os estudos que buscam apreciar as crianças a partir da sua realidade social, da cultura afetiva que estão inseridas e que, também, são capazes de construir. Busca-se analisar a realidade afetiva vivenciada por crianças, no ambiente sociocultural. Como objeto de estudo foi utilizado os registros em eventos de brincadeiras infantis em parques e ambientes públicos, na capital mineira. O Programa "Escola Livre de Artes Arena da Cultura em Belo Horizonte" executa o projeto "Brinquedos e Brincadeiras". Este projeto está contribuindo no fortalecimento de relações sociais com o ambiente em diversos espaços públicos, na cidade de Belo Horizonte. De forma gradual, o Programa "BH é da Gente" executa atividades de recreação infantil para a comunidade, valorizando a cultura local. A diversidade geográfica e cultural são instrumentos para a experimentação de novas formas do brincar. Em considerações, pode-se dizer que, a brincadeira é sempre um produto coletivo e inovador. Pois, aquele que brinca é um agente ativo deste processo, contribuindo para a produção de culturas particulares entre os brincantes, em cada ambiente.
\end{abstract}

Palavras-chave: Cultura afetiva; brincadeiras coletivas; criança; espaço público urbano, Cidade Belo Horizonte.

\section{Resumen}

La transformación de los espacios en lugares de afecto es una posibilidad que surge de las relaciones en la diversión y el juego. Esta relación puede proporcionar una reflexión sobre el comportamiento humano y generar nuevas vías para la participación social. Se utilizan estudios que buscan apreciar a los niños desde su realidad social, la cultura afectiva en la que se insertan y que también pueden construir. Buscamos analizar la realidad afectiva que experimentan los niños en el entorno sociocultural. Como objeto de estudio se utilizaron los registros en eventos de juegos infantiles en parques y ambientes públicos en la capital de Minas Gerais. El programa "Escuela Libre de Artes de la Arena de la Cultura en Belo Horizonte" ejecuta el proyecto "Juguetes y juegos". Este proyecto está contribuyendo al fortalecimiento de las relaciones sociales con el medio ambiente en diversos espacios públicos de la ciudad de Belo Horizonte. Poco a poco, el programa "BH é da Gente" realiza actividades de recreación infantil para la comunidad, valorando la cultura local. La diversidad geográfica y cultural son instrumentos para experimentar con nuevas formas de juego. En términos de consideraciones, se

\footnotetext{
1 Artigo apresentado no I Congresso Internacional Online de Estudos sobre Culturas, na modalidade online, 2019.

2 Doutora em Design; Universidade do Estado de Minas Gerais; Belo Horizonte, Minas Gerais, Brasil; nadjamourao@gmai.com.

3 Mestra em Design; Universidade do Estado de Minas Gerais; Belo Horizonte, Minas Gerais, Brasil; anaceliadesign@gmail.com.
} 
puede decir que el juego es siempre un producto colectivo e innovador. Porque quien juega es un agente activo de este proceso, contribuyendo a la producción de culturas particulares entre los jugadores, en cada lugar.

Palabras clave: Cultura afectiva; juegos colectivos; niño espacio público urbano, ciudad de Belo Horizonte.

\begin{abstract}
The transformation of spaces into places of affection is a possibility that comes from relationships in fun and play. This relationship can provide a reflection on human behavior and generate new avenues for social participation. Studies are used that seek to appreciate children from their social reality, the affective culture they are inserted and that are also able to build. We seek to analyze the affective reality experienced by children in the socio-cultural environment. As object of study was used the records in events of children's play in parks and public environments in the capital of Minas Gerais. The Program "Free School of Arts Arena of Culture in Belo Horizonte" executes the project "Toys and Play". This project is contributing to the strengthening of social relations with the environment in various public spaces in the city of Belo Horizonte. Gradually, the "BH é da Gente" Program performs activities for children recreation for the community, valuing the local culture. Geographic and cultural diversity are instruments for experimenting with new forms of play. In terms of considerations, it can be said that play is always a collective and innovative product. Because, the one who plays is an active agent of this process, contributing to the production of particular cultures among the players, in each environment.
\end{abstract}

Keywords: Affective culture; collective games; kid; urban public space, Belo Horizonte City.

\title{
1. Introdução
}

Por meio das brincadeiras infantis, reflete-se a possibilidade de transformar espaços em lugares de afeto. Esta relação entre o ambiente e as brincadeiras de crianças pode gerar novas percepções e condições para a participação social. Conforme Benjamim (1984), o conhecimento de algumas atividades sociais e desenvolvimento da capacidade de formação do caráter, também podem ser adquiridos por meio do brincar. A transmissão de saberes populares em grupos sociais ocorre em experiências vivenciadas e dificilmente serão repassadas através de métodos didáticos.

A essência do brincar não é um "fazer como se", mas um "fazer sempre de novo", a transformação da experiência mais comovente em hábito. Pois é o jogo, e nada mais, que dá à luz a todo o hábito. Comer, dormir, vestir-se, lavar-se deve ser inculcado no pequeno irrequieto por meio da brincadeira, que são acompanhadas pelo ritmo dos versinhos. Formas petrificadas e irreconhecíveis de nossa primeira felicidade, de nosso primeiro terror, eis os hábitos (BENJAMIN, 1984, p. 75).

Neste trabalho, busca-se analisar os estudos que apreciam a realidade vivenciada por crianças, a partir do ambiente social e da cultura afetiva onde estão inseridas. A pesquisa apresenta recortes de estudos sobre o "design para a felicidade" em espaços urbanos externos, ou seja, em paisagem urbana, ideais para atividades recreativas. Trata-se de contextos de atuação do design, com foco na felicidade das pessoas. Em objeto de estudo, foram utilizados registros de brincadeiras infantis em eventos nos parques e ambientes públicos, realizados na cidade de Belo Horizonte/MG, no período de 2017 a 2019. 
O estudo do ambiente público urbano está inserido nas análises sobre os ambientes onde as crianças vivenciam momentos lúdicos no cotidiano das cidades. Aborda-se, fundamentalmente, a compreensão do brincar e das brincadeiras infantis, uma vez que, as suas peculiaridades e métodos de organização podem impactar a conduta de uso destes espaços pelas crianças. Busca-se averiguar se estes ambientes proporcionam alguma relação com os usuários e vice-versa.

As características próprias do meio em que as brincadeiras acontecem refletem na sua forma simbólica de expressão, isto é, cada cultura possui diferenciações no brincar, embora esta seja uma atividade universal (MORAES; OTTA, 2003). A brincadeira é uma atividade coletiva e inovadora, pois, aquele que brinca é um agente ativo deste processo, estimulando a formação de culturas particulares e exclusivas, entre os brincantes (CORSARO, 1985).

Dessa forma, as brincadeiras nos parques públicos e nos centros culturais de bairros de periferia, tornaram-se parte do Programa "Escola Livre de Artes Arena da Cultura em Belo Horizonte", em eventos anuais. Conforme informações da Prefeitura de Belo Horizonte (2019), o projeto denominado "Brinquedos e Brincadeiras" têm como objetivo promover encontros permanentes que possibilitam aos participantes momentos lúdicos de interação social e contato com a cultura da infância, a partir do ato de brincar.

$\mathrm{Na}$ figura 1, apresenta-se uma imagem de crianças brincando de cabo-de-guerra. Trata-se de uma das atividades da programação do projeto "Brinquedos e Brincadeiras", em espaços públicos de Belo Horizonte.

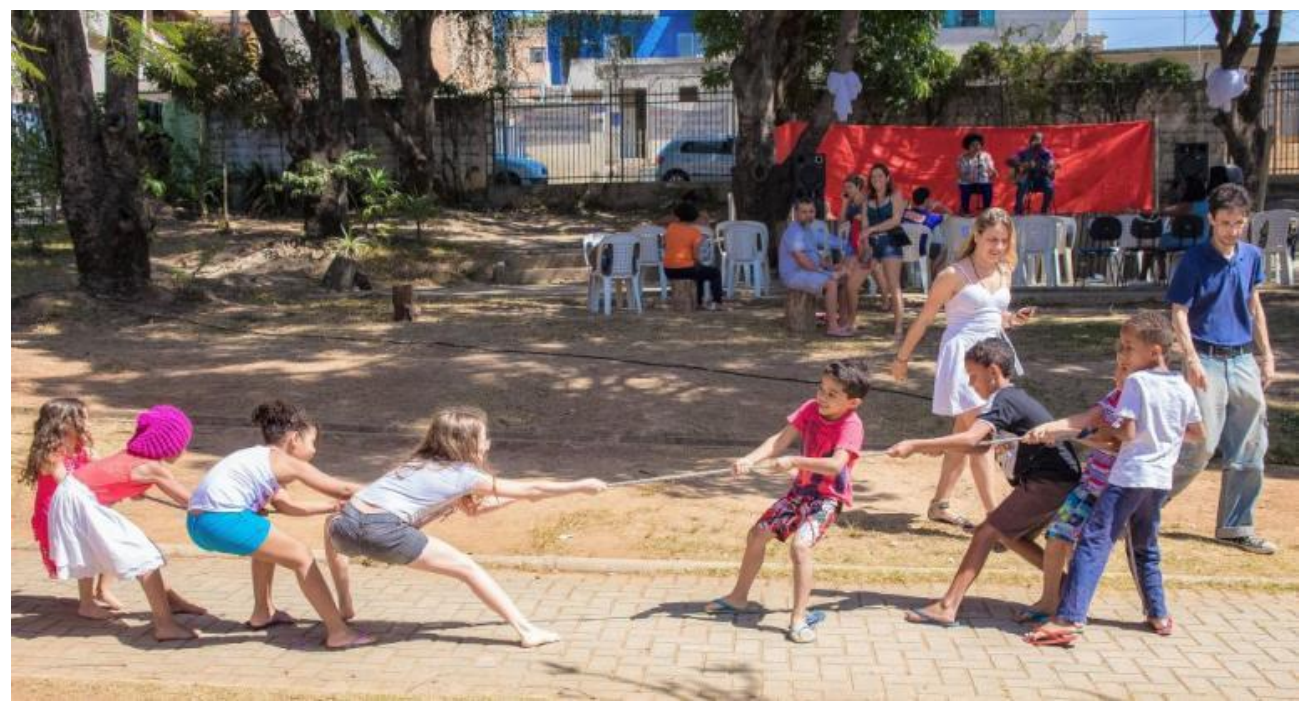

Figura 1 - Crianças brincando de cabo-de-guerra.

Fonte: https://prefeitura.pbh.gov.br/index.php/noticias/pbh-prepara-programacao-especial-de-ferias-nos-centrosculturais-e-bibliocas. 
A brincadeira "cabo de guerra" se faz pela divisão dos participantes em número equivalente, em dois lados opostos. Sendo que, em cada lado, as pessoas deverão puxar uma única corda entre eles. Existe um limite de território da brincadeira, que é um marco mediano, onde se estabelece até onde cada equipe pode chegar. Geralmente, esta marca é feita por giz escolar no chão ou com um cabo de vassoura. Cada equipe deverá puxar uma das pontas da corda sem ultrapassar este limite. A Equipe que conseguir puxar a corda com os membros da outra equipe, além da marca estabelecida como limite, é considerada a vencedora.

Durante a programação do evento desenvolvido pela Secretaria Municipal de Cultura e da Fundação Municipal de Cultura, as crianças e suas famílias são estimuladas a vivência de brincadeiras populares, valorizando a participação infantil na cultura local. O programa ainda prevê o reconhecimento das artes e dos elementos da cultura brasileira, presente nas brincadeiras.

\section{Cultura afetiva}

O homem é um indivíduo social que utiliza de relações sociais no seu processo evolutivo. As relações sociais são elementos fundamentais, de forma que a sua investigação é básica para a área da psicologia positiva do desenvolvimento (BUSSAB, 2003). A psicologia positiva utiliza-se de métodos tradicionais da verificação psicológica, como também de recursos inovadores no campo da neurociência para o estudo das emoções e do comportamento humano. Dessa forma, ela opta pelo caminho da investigação baseada na experiência, respeitando os rigores da metodologia científica e suas análises em dados tangíveis, segundo estudos do psicólogo americano Martin Seligman (2009).

Pensando na felicidade das crianças e na construção de sua cultura afetiva, os trabalhos de Huebner e Gilman (2002) sobre a satisfação de vida infantil apresentaram cinco domínios específicos nessa abordagem: família, amizade, escola, ambiente e self. Os autores avaliaram como a criança constrói a idéia de ser feliz reconhecendo outra pessoa feliz, ou seja, a criança percebe a sua felicidade na felicidade de outrem. Suas amizades são envolvidas na emoção de alegria, percebendo as qualidades dos seus amigos na realização de boas brincadeiras (GARCIA; PEREIRA, 2008).

As emoções podem gerar as escolhas do ser humano, pois elas fazem parte do campo das opções. Norman (2008) diz que as emoções servem, inclusive, de direção para o comportamento humano. Segundo ele, quem entra em ação nessa hora é o sistema afetivo - o responsável, em nosso organismo, por julgar o que é bom ou ruim, seguro ou perigoso. Nada 
a ver com a razão ou com a lógica. Para o autor a explicação para esse fenômeno é simples: quando o ser humano se depara com algo que julga atraente, isso motiva uma sensação de bem-estar.

Dessa forma, trata-se de um lugar passível de ser sentido, pensado, acomodado e vivido por meio do corpo, capaz de trazer emoções positivas, bem-estar e felicidade (GIACOMONI; SOUZA; HUTZ, 2014). Entende-se que um espaço vivido, mesmo que este lugar seja considerado socialmente degradado, na perspectiva das crianças sobre este ambiente, há um vinculo de pertencimento, por se apropriarem dos espaços livres articulando situações reveladoras da identidade do lugar.

Segundo estudos de Piaget e Inhelder (1993) em relação a lugares com crianças; essas já nascem envolvidas em uma rede de significados com o mundo; e à medida que crescem e desenvolvem seus sentidos, tomam cada vez mais consciência de si e de tudo que a rodeiam; assim constroem noções de espaço-tempo.

De acordo com o Lopes (2013), no início, a criança apenas entende o espaço com seu corpo interagindo com objetos usando seus sentidos. Neste momento, o seu espaço de vivência são os lugares e os objetos onde ela brinca. As relações espaciais das crianças crescem e se tornam mais envolventes à medida que ela amplia seu campo de ação.

Neste sentido, Piaget (1993) relata uma série de etapas sucessivas pelas quais o ser humano passa na sua construção da noção espacial. Primeiramente, as relações de perto e longe, estas são relações de vizinhança; em seguida, as relações de separação, onde identificam que os objetos ocupam lugares marcados no espaço; depois, a ordem e o fechamento, onde tem a noção de interior e exterior. $\mathrm{O}$ autor completa ainda que são estas as relações topológicas que antecedem as relações projetivas onde se destacam direitas, esquerda, eixos e coordenadas do observador.

O ser humano ao longo de sua permanência em configuração urbana, gradativamente, vai reconhecendo as vias, os caminhos para se deslocar, os limites, contornos, bairros, pontos nodais e seus lugares de encontro como, praças, marcos, todos identificados por detalhes memoráveis. Neste envolvimento, evidencia-se que as pessoas desenvolvem mapas mentais, construídos por seus ensaios e histórias de vida (LYNCH, 1960).

Mapas mentais ajudam a criar conexões no pensamento humano, assim podendo familiarizar-se com espacialidades, gerando lugares de afeto, lugares seguros e com 
identidade. Segundo o psicólogo e escritor Buzan (2009) são registros mentais ligados a imagens e cores, o que ajudam a memorizar.

\section{Lugares de afeto}

Os lugares, percebidos como espaços onde as pessoas estabelecem relações afetivas, fornecem uma extensa perspectiva para os estudos da cultura afetiva, principalmente para as pesquisas em design. A noção de topofilia, desenvolvida por Tuan (1980), aborda essa amplitude não somente na área da geografia, mas também no campo da afetividade.

O termo topofilia, ao ser abrangido como o "[...] elo afetivo entre a pessoa e o lugar ou ambiente físico" (TUAN, 1980, p. 5), diz a existência de uma contestação entre espaço e lugar, ambos às vezes se misturam, porém “[...] 'espaço' é mais abstrato que 'lugar'. O que começa como espaço indiferenciado transforma-se em lugar à medida que o conhecemos melhor e dotamos de valor".

Nas últimas décadas, o tempo e o espaço destinados às crianças foram essencialmente modificados em função de graves fenômenos bastante conhecidos, quais sejam: a violência, a presença de estranhos, drogas, atividades ilícitas, tráfego de veículos, entre outros fatores que parecem ser ameaças universais no mundo moderno (COTRIM; BICHARA, 2013, p. 389).

Como consequência dos riscos gerados nos centros urbanos, o brincar natural na infância passou por modificações em sua essência. As crianças deixaram de usufruir da liberdade do brincar em espaços públicos, distantes agora do cotidiano infantil (KARSTEN; VLIET, 2006). Para proteger as crianças e jovens foram projetados ambientes diferentes daqueles compartilhados entre elas, em criativa experimentação dos elementos do entorno.

No Brasil existem lugares onde "um jogo de forças sociais" que dita suas próprias leis e códigos culturais (PERLMAN, 1977, p.40). Ou seja, expressa pela necessidade de habitar a "custo zero" e que consolida territórios diferenciados, por estarem à margem da cidade instituída pelas leis e normas urbanísticas. Lugares aglomerados (favelas) e periferias caracterizam-se como espaços marginalizados, com sua coerência de ocupação diferenciada da cidade instituída (DUARTE et al., 1996).

Desse modo, por meio das brincadeiras as crianças que vivem nas favelas e periferias humanizam os lugares públicos e contribuem para a formação da identidade cultural, interagindo com a imagem apreendida de sua ambiência. Assim, é possível dizer que a diferença entre os tipos de brincadeiras em lugares públicos pode estar associada aos espaços físicos que sugerem brincadeiras distintas. O espaço é um fator importante na escolha das 
brincadeiras coletivas, a partir das tradições e da cultura dos brincantes no desenvolvimento das atividades lúdicas (COTRIM et al., 2009).

Diferentemente das crianças que possuem uma experiência mais restrita aos espaços privados, as crianças que vivem em aglomerados e periferias circulam e brincam fora de casa, com seus pares, em espaços comuns (PÉREZ; JARDIM, 2015). As crianças que brincam nas proximidades de suas casas desenvolvem uma relação de pertencimento com lugar onde moram. Elas podem se adaptar com as incoerências por serem parte do cotidiano, assim como as questões locais. Através da ação e brincadeira, elas alteraram os espaços em lugares de afeto, o que harmoniza um olhar intricado para a sua realidade e constrói novas portas para a participação social.

Matthews (2003) concorda com essa análise, ao dizer que na rua as crianças cultivam tempo ao entendimento dos seus pares permitindo usos diferenciados de ocupação do espaço urbano, com possíveis encontros com crianças de idades diferenciadas, de ambos os gêneros, levando a entender a perspectiva social das relações e das posições. Vivenciar as brincadeiras de rua é ter a oportunidade de perceber a transposição da infância para a vida adulta. As brincadeiras de rua permitem que a criança desenvolva competências sociais.

Segundo Castro (2001), a criança contribui no processo de produção e reprodução da cultura pelo seu atuar, sua maneira de interferir no mundo, assim como os adultos. A subjetividade da criança se edifica, aos poucos, a partir de suas ações, que reconstroem e recriam o que está ao seu redor.

Assim, também as suas parcerias de brincadeiras, são análogas à maneira de interação dos adultos. Normalmente, a criança busca extrair a relação pelo desempenho do parceiro e combina-se com o outro às suas ações. Desse modo, a criança ergue, ativa e conjuntamente, atividades, circunstâncias e conhecimento compartilhados nas brincadeiras (CARVALHO, 1994).

O cotidiano das crianças em aglomerados e periferias é transcorrido pelas redes de relações construídas na vizinhança, na escola, na família, entre outros.

[...] nessa favela elas se sentem seguras para perambular, explorar e conviver, nos diferentes espaços. Enquanto a casa remete ao polo dos adultos, em que as crianças se encontram submetidas às normas e regras familiares, os becos, praças e vielas remetem ao polo de convivência com os pares, onde elas podem construir suas próprias regras, mediante os jogos e as brincadeiras. As crianças ocupam a favela, marcando o seu território de domínio e transformando-o em um lugar. (PÉREZ; JARDIM, 2015, p. 495). 
Essas crianças possuem uma rede de amizades, uma rede afetiva e familiar no lugar favela, onde se sentem seguras livres e podem se aventurar, o que contribui para a construção de raízes próprias em ação coletiva. A criança busca "experimentar todo o espaço que está ao seu alcance e se identifica nele mediante suas conquistas, descobertas e diferentes ações" (COELHO, 2007, p. 178). Ao interatuarem com os espaços de aglomerados e periferias, as crianças também influenciam na história coletiva, com o sistema de ideias, e edificam um conhecimento fortemente cultural.

O Programa BH é da Gente leva o contexto das brincadeiras antigas, cantadas em rodas, jogos de tabuleiro, pula-corda, bambolê, amarelinha, entre outras. Também há apresentações musicais e outras atividades, para manter o vínculo da comunidade local. Tratase de um programa recreativo em espaço público urbano, que acontece aos domingos, em alguns bairros da cidade. O programa conduz também a prática de atividades físicas, esportivas e de lazer ao ar livre, bem como a convivência e a cidadania em vias e locais públicos. Busca promover a ocupação dos espaços públicos pela população, conduzindo as relações de pertencimento para proteção social. Na figura 2, um registro das atividades nas ruas próximas da "Pedreira Prado Lopes", um imenso aglomerado próximo ao Bairro Lagoinha/Belo Horizonte (figura 2).

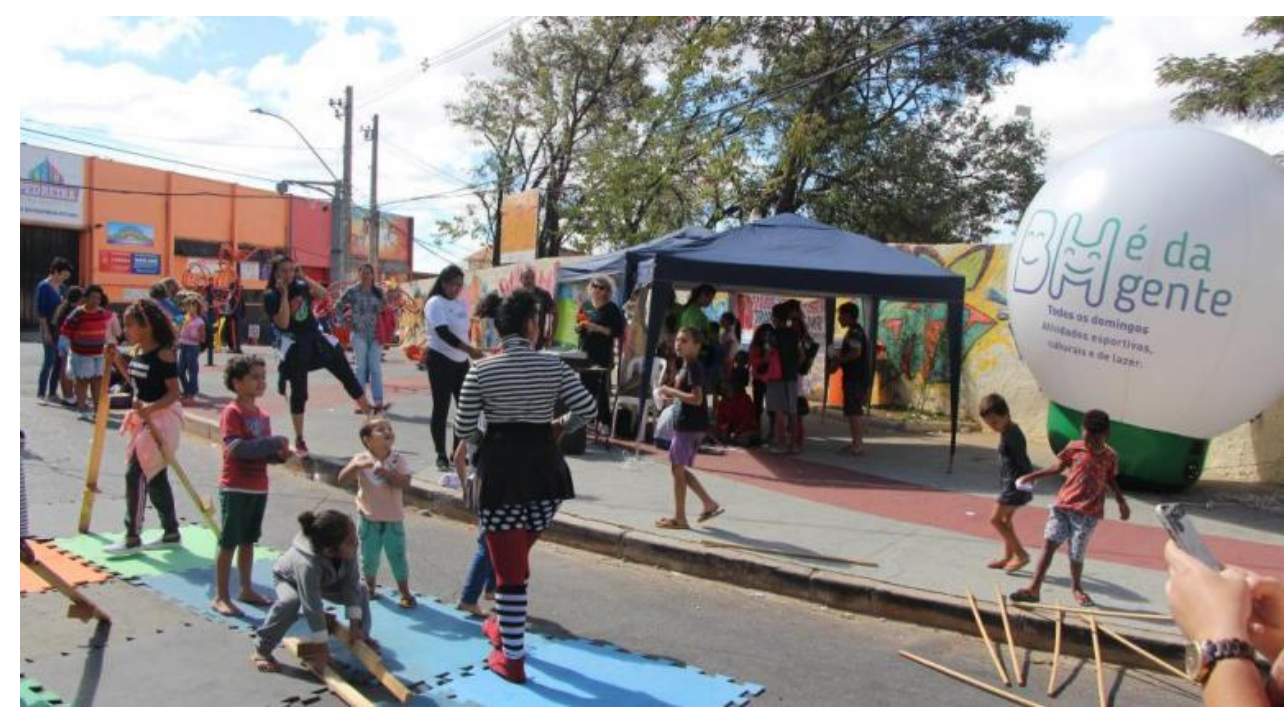

Figura 2 - Crianças brincando no Programa BH é da Gente - Pedreira Padre Lopes.

Fonte: https://prefeitura.pbh.gov.br/noticias/bh-e-da-gente-cumpre-funcao-de-protecao-social-na-pedreira-pradolopes.

É possível destacar que o lugar onde os seus humanos entrelaçam suas relações, mesmo sendo criticado por pessoas externas, harmoniza o aparecimento e a sustentação de laços afetivos entre as pessoas e o lugar, justificando a ideia do sentimento de bairrismo que se observa nos moradores de um centro urbano. 
Esse aspecto aproxima-se do pensamento de Tuan (1980) sobre a topofilia, no qual as pessoas são capazes de construir afinidades afetuosas com o lugar onde vivem. Assim, os moradores não se preocupam com as qualidades físicas do espaço, e sim, as relações que revolvem seu lugar familiar. $\mathrm{O}$ autor ainda completa que, o lugar é pausa, segurança quando as pessoas se identificam e criam laços afetivos. Essa pausa identitária ocorreu porque as relações com o lugar possibilitou a segurança que, possivelmente, não seria encontrada onde não há relação com o ambiente.

Constata-se que, "quando o espaço nos torna inteiramente familiar torna-se lugar". Corrobora-se a ideia que as pessoas são livres para circular entre espaços e à medida que percebem determinados espaços a sua maneira, aos seus valores e à sua identidade, esse espaço, a elas, se oferece como um lugar (TUAN, 1983, p. 83).

Nos aglomerados e periferias as características do espaço são peculiares. Observa-se que a utilização de seus espaços livres pelas crianças se destina a várias finalidades no momento da brincadeira, transformando-os em lugares ideais ao brincar na criatividade infantil.

Os programas que levam as brincadeiras para os ambientes de vivência das comunidades proporcionam apropriação destes espaços. Ao mesmo tempo em que o ambiente se caracteriza pelos processos de apropriação dos eventos infantis. Assim, são lugares de afeto, que se preservam na memória das crianças e dos membros da comunidade local.

\section{Ser brincante urbano - a geografia da infância}

A brincadeira e os possíveis objetos que fazem parte dela estão marcados pela identidade cultural e por características sociais específicas de uma comunidade urbana. As ruas são lugares que podem adquirir valores simbólicos para uma sociedade urbana. Ou seja, o urbano externo torna-se o lugar que resgata a experiência da diversidade e possibilita a presença do estranho, o encontro entre desconhecidos, a permuta entre diferentes, a identificação dos iguais, a variedade de usos e olhares (DA MATTA, 1985).

$\mathrm{Na}$ área do conhecimento da geografia, o contexto urbano externo tem sido bastante lembrado por diversos pesquisadores ao redor do mundo, como fonte para o comportamento infantil (ELLIS, 2004; KARSTEN, 2003; RASMUSSEN, 2004). Colonna e Brás (2011) historiam o nascimento de uma área especial de investigação, a geografia da infância, que parte do princípio de que as "espacialidades" têm grande valor no cotidiano das crianças em sociedade. 
Em espaços urbanos externos podem-se encontrar sinais da natureza, bem como seus ciclos e elementos, capazes em criar relações essenciais e simbólicas com o crescimento das crianças, segundo Mendonça (2019). Assim, surge uma relação direta com o crescimento e a formação do corpo das crianças. São também recursos de aprendizado oriundo da experiência. "A criança busca por autonomia desde que nasce, e é no brincar livre na natureza que ela encontra o cenário ideal para exercer essa pulsão de vida. Assumir riscos é inerente ao brincar ao ar livre, e uma condição para o desenvolvimento sadio das crianças". São ações de ir além dos limites conquistados, em terrenos acidentados e em constante movimento, na velocidade que a idade trás; fortalecendo assim, suas destrezas físicas e emocionais (MENDONÇA, 2019, p.12).

A sociedade contemporânea é predominantemente urbana. As crianças, em sua maioria, nascem e crescem em contextos urbanos. No Brasil, $84 \%$ da população vivem em cidades (IBGE, 2016) e 47\% das pessoas não se sentem seguras na cidade em que moram (IBGE, 2016). Desta forma, na atualidade, ocorre uma mudança na relação das crianças com o espaço público e natural, segundo o pesquisador e jornalista Richard Louv (2005). O termo "Transtorno do Déficit de Natureza", criado por Louv (2005), busca delinear o não envolvimento entre a criança e a natureza e os concludentes conflitos negativos na saúde e bem-estar entre os afetados e o planeta.

Segundo Lopes (2013), pode-se situar a década de 1970 como um momento em que se começam os acúmulos de trabalhos (atividades) que envolvem as crianças e suas espacialidades. Produções desenvolvidas em diferentes contextos geográficos e intensamente influenciadas pelos requeridos na geografia humanista provocaram uma série de ações e apontamentos, que condicionam o bem-estar das crianças no espaço. No final da década de 1980 e os anos 1990 ocorreram mudanças legais que passaram a incluir as crianças, como sujeitos de direitos.

Exemplificando, destaca Lopes (2013),

[...] a Convenção sobre o Direito das Crianças e muitos outros documentos (por exemplo, o ECA no Brasil) possibilitam outros estatutos para a infância e estendem a ideia do direito da criança ao espaço e, assim, um outro foco ganha força nos estudos da Geografia da Infância, a noção de território, de espaço como direito politicamente definido (LOPES, 2013, p. 290).

Em Belo Horizonte, como exemplo de projeto de ação, existe um movimento social chamado "BH pela infância", que incentiva a reflexão sobre a cidade e a criança, integrando o 
debate sobre educação, cultura, alimentação, saúde e sustentabilidade. Discutem como a cidade dialoga com a infância, entendendo suas necessidades, para a construção de espaços públicos que sejam interessantes, acessíveis e seguros para elas. Acreditam em uma construção coletiva de uma cidade que verdadeiramente veja as crianças como habitantes.

Entre as questões que o movimento social "BH pela Infância" busca solucionar, podem ser citadas: apoiar a promoção de políticas públicas relacionadas à infância e à construção de uma cidade mais verde, mais segura, mais acessível e mais humana; incentivar o brincar na cidade; debater sobre a importância do cuidado com os espaços públicos para adultos e crianças; contribuir para a ampliação de ações sustentáveis pela cidade; incentivar a participação das pessoas na construção de uma cidade melhor para todos; estimular uma cidade que respeite a infância de forma integral.

As ruas de lazer (figura 3) são exemplos de como as crianças podem ter uma relação de vivência com o ambiente, convivendo melhor com o espaço para brincar.

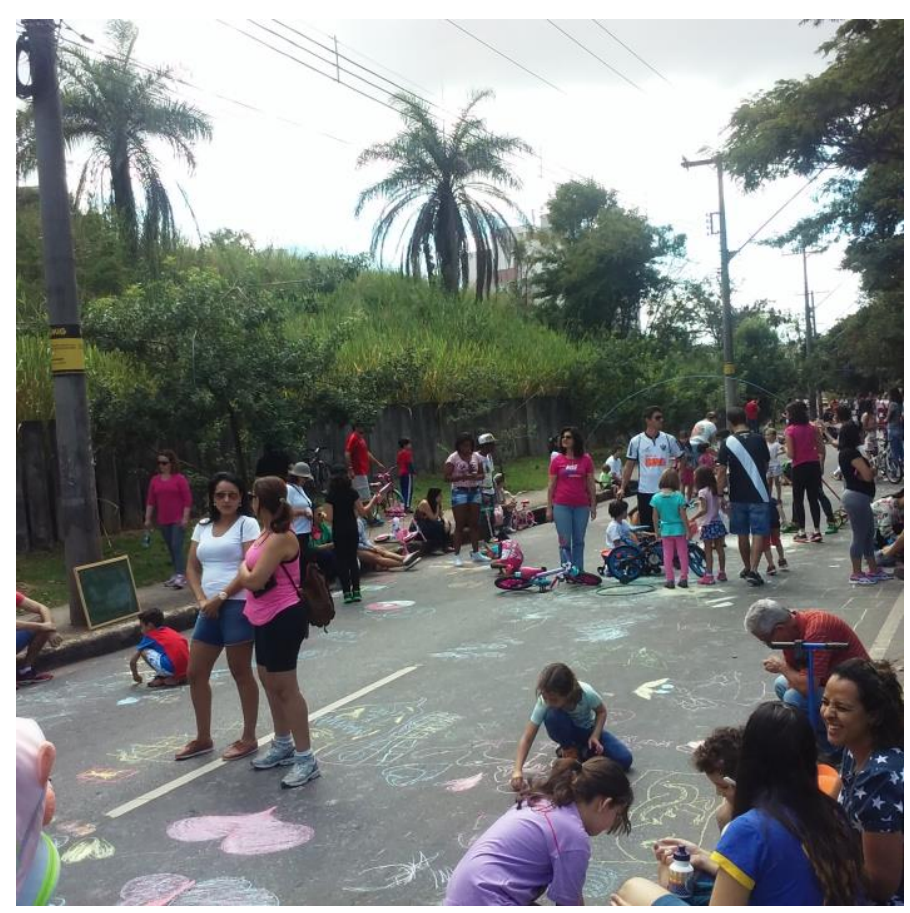

Figura 3 - Crianças brincando no evento Brincaço BH, Rua José Candido da Silveira. Bairro União/BH-MG.

Fonte: https://bhpelainfancia.com.br/cidade/brincaco-em-bh-reivindica-mais-espaco-para-a-infancia/.

A Geografia Humanista busca abarcar a percepção e representação do espaço por indivíduos, percebendo seu caráter único, singular, ao mesmo tempo em que distingue o seu pertencimento e compartilhamento a um apurado grupo cultural. Tuan (1982) manifesta essas condições ao definir o caráter desse movimento: 
A Geografia Humanística reflete sobre os fenômenos geográficos com o propósito de alcançar melhor entendimento do homem e de sua condição. [...] procura um entendimento do mundo humano através das relações das pessoas com a natureza, do seu comportamento geográfico bem como dos sentimentos e ideias a respeito do espaço e do lugar. (TUAN, 1982, p. 143).

Dessa forma, o brincar é um ato que relaciona o ser humano com sua realidade e com outras pessoas. Esta atividade está inserida na vivência com o espaço físico, lugares imaginários em condições afetivas. Realizar brincadeiras também proporciona sentimentos diversos, na maioria por diversão e alegria.

Tuan (1980) relata que o brincar é uma atividade muito interessante e única na construção do imaginário humano. Todos os seres humanos compartilham percepções comuns em virtude de possuírem estrutura biológica similar. Mas, algumas características psicológicas diferenciam a percepção humana: “[...] os objetos que percebemos são proporcionais ao tamanho do nosso corpo, à acuidade e amplitude do nosso aparelho perceptivo e ao propósito" (TUAN, 1980, p. 16).

\section{Considerações finais}

Considera-se a brincadeira um produto coletivo e inovador, uma vez que quem brinca é um agente ativo desse processo e contribui para a produção de culturas particulares entre os brincantes. As crianças se apropriam dos ambientes urbanos externos, públicos por meio das brincadeiras e estes ambientes também se modificam pela ação de brincar das crianças.

A infância nos aglomerados (favelas) e periferias é caracterizada pela brincadeira fora de casa concretizada coletivamente com os pares e pelo convívio com a natureza. Por meio das brincadeiras, as crianças se ocupam do espaço da favela e geram modificações no comportamento das pessoas envolvidas nestes ambientes, como também proporcionam relações de afetos e identidade com o ambiente. Assim, brincar livremente é importante para que as crianças possam vivenciar diversas situações, conhecendo o espaço e as pessoas do lugar.

Em metrópoles como Belo Horizonte, percebe-se modos distintos de ocupação do espaço urbano por crianças. Os programas desenvolvidos com apoio da prefeitura contribuem para desenvolver uma nova relação da comunidade com o espaço público. O Programa "Escola Livre de Artes Arena da Cultura em Belo Horizonte", executa o projeto "Brinquedos e Brincadeiras" que está contribuindo com as relações sociais com o ambiente em diversos espaços públicos em Belo Horizonte. O Programa BH é da Gente de forma gradual, leva 
atividades de recreação (infantil) de valorização da região e da cidade. A diversidade geográfica e cultural é palco de diversas formas e conteúdo de brincadeiras.

\section{Referências}

BENJAMIM, W. Reflexões: A Criança o Brinquedo e a Educação. São Paulo, Summus Editorial, 1984.

BH PELA INFÂNCIA. O que queremos? Disponível em: https://bhpelainfancia.com.br/oque-queremos/. Acesso em: 22 nov. 2019.

BUSSAB, V. S. R. Afetividade e interação social em crianças: perspectiva psicoetológica. 2003. Tese (Livre-docência em Psicologia) Instituto de Psicologia, Universidade de São Paulo, São Paulo, 2003.

BUZAN, T. Mapas Mentais. Rio de Janeiro: Sextante, 2009.

CARVAlHO, A. M. A. O que é "social” para a psicologia? Revista Temas em Psicologia, v. 3, 1994.

CASTRO, L. R. Crianças e jovens na construção da cultura. Rio de Janeiro: Nau, 2001.

COELHO, G. N. Brincadeiras na favela: a constituição da infância nas interações com o ambiente. In: VASCONCELLOS, V. M. R; SARMENTO, M. J. (Orgs.). Infância (in)visível. Araraquara: Junqueira \& Marin, 2007.

COLONNA, E.; BRÁS, E. J. Crianças e espaço urbano em Maputo. In: MÜLLER, V. R. (Ed.). Crianças dos países de língua portuguesa: Histórias, cultura e direitos. Maringá: Editora da Universidade Estadual de Maringá, 2011.

CORSARO, W. Friendship end peer in the early years. Norwood: Ablex, 1985.

COTRIM, G. S. et al. Espaços urbanos para (e das) brincadeiras: um estudo exploratório na cidade de Salvador (BA). Psicologia: teoria e prática, São Paulo, v. 11, 2009.

; BICHARA, I. D. O brincar no ambiente urbano: limites e possibilidades em ruas e parquinhos de uma metrópole . Revista Psicologia, Reflexão e Critica [online]. vol.26, n.2, 2013, p. 388-395. DOI: http://dx.doi.org/10.1590/S0102-79722013000200019.

DA MATTA, R. A casa e a rua. São Paulo: Brasiliense, 1985.

DUARTE, C. R. et al. Favela, um bairro. São Paulo: Proeditores, 1996.

ELLIS, J. Researching children's place and space. Journal of Currículum Theorizing, $\mathrm{n}^{\mathbf{0}} 20$, vol.1, 2004.

GARCIA, A.; PEREIRA, P. Amizade na infância: um estudo empírico. Psic. Revista de Psicologia. Vetor Editora, nº. 9, vol. 1, 2008. 
GIACOMONI, C. H.; SOUZA, L. K.; HUTZ, C. S. A visão das crianças sobre a felicidade. Revista Quadrimestral da Associação Brasileira de Psicologia Escolar e Educacional, SP. Volume 18, Número 1, Janeiro/Abril de 2014, p.143-150, 2014. Disponível em: http://www.scielo.br/pdf/pee/v18n1/v18n1a15.pdf. Acesso em: 20. nov. 2019.

HUEBNER, E. S; GILMAN, R. An introduction to the multidimensional student's life satisfaction scale. Social Indicators Research, $\mathrm{n}^{\circ}$ 60, 2002.

IBGE - INSTITUTO BRASILEIRO DE GEOGRAFIA E ESTATÍSTICA. Síntese de indicadores sociais: uma análise das condições de vida da população brasileira, 2016. Rio de Janeiro: IBGE - Coordenação de População e Indicadores Sociais, 2016.

KARSTEN, L. Children's use of public space: The gendered world of the playground. Childhood (London), nº10, vol.4, 2003.

; VLIET, W. Children in the city: Reclaiming the street. Children, Youth and Environments, $\mathrm{n}^{\mathrm{o}} 16$, vol.1, 2006.

LOPES, J. J. M. Geografia da Infância: contribuições aos estudos das crianças e suas infâncias. In: Revista Educação Pública. Cuiabá v. 22 n. 49/1, 2013.

LOUV, R. A Última Criança na Natureza. São Paulo: Aquariana, 2005.

LYNCH, K. The Image of the City. Cambridge: M. I. T. Press, 1960.

MATTHEWS, H. The street as a liminal space: The barbed spaces of childhood. In P. Christensen \& M. O'Brien (Eds.), Children in the city: Home, neighborhood and community. New York: Routledge, 2003.

MENDONÇA, P. A Natureza que ensina. Disponível em: http://conexaoplaneta.com.br/blog/a-natureza-que-ensina/. Acesso em: 24 nov.2019.

MORAES, M. S.; OTTA, E. Entre a serra e o mar. In: CARVALHO, A. M. A.; MAGALHÃES, C. M. C.; PONTES, F. A. R.; BICHARA; I. D (Org.). Brincadeira e cultura: viajando pelo Brasil que brinca. São Paulo: Casa do Psicólogo, 2003.

NORMAN, A. D. Design emocional. Por que adoramos (ou detestamos) os objetos do dia-adia. Rio de janeiro: Rocco, 2008.

PEREZ, B. C.; JARDIM, M. D. Os lugares da infância na favela: da brincadeira à participação. Revista Psicologia Social [online]. $\quad$ Vol. $27, \quad$ n.3, 2015. DOI: http://dx.doi.org/10.1590/1807-03102015v27n3p494.

PERLMAN, J. E. O mito da marginalidade: favelas e políticas no Rio de Janeiro. Rio de Janeiro: Paz e Terra, 1977.

PIAGET, J. ; INHELDER, B. A representação do espaço na criança. Porto Alegre: Artes Médicas, 1993.

PREFEITURA DE BELO HORIZONTE. Disponível em: https://prefeitura.pbh.gov.br/. Acesso em: 20 nov. 2019. 
PROGRAMA BH É DA GENTE. Disponível em: https://prefeitura.pbh.gov.br/noticias/bh-eda-gente-cumpre-funcao-de-protecao-social-na-pedreira-prado-lopes. Acesso em: 20 nov. 2019.

PROGRAMA ESCOLA LIVRE DE ARTES ARENA DA CULTURA EM BELO HORIZONTE. Disponível em: https://prefeitura.pbh.gov.br/index.php/noticias/pbh-preparaprogramacao-especial-de-ferias-nos-centros-culturais-e-bibliocas. Acesso em: 20 nov. 2019.

RASMUSSEN, K. Places for children-Children's places. Childhood, nº11, vol.2, 2004.

SELIGMAN, E. P. M. Authentic Happiness: Using Positive Psychology to Realization Permanent. Rio de Janeiro: Objetiva, 2009.

TUAN, Yi-Fu. Espaço e lugar - a perspectiva da experiência.. Rio Claro: Difel, 1983.

Geografia Humanística. In: CHRISTOFOLETTI, A. Perspectivas da Geografia. São Paulo: Difel, 1982.

Topofilia. Um estudo da percepção, atitudes e valores do meio ambiente. São Paulo: Difel, 1980. 